\title{
Erratum to: Reduction in external ventricular drain infection rate. Impact of a minimal handling protocol and antibiotic-impregnated catheters
}

\author{
Mónica Rivero-Garvía • Javier Márquez-Rivas • \\ Manuel Enrique Jiménez-Mejías • Olaf Neth • \\ Ana Belén Rueda-Torres
}

Received: 11 February 2011 / Published online: 26 February 2011

(C) Springer-Verlag 2011

\section{Erratum to: Acta Neurochir}

DOI 10.1007/s00701-010-0905-1

There was an error in reference no. 9.: Gutiérrez-González R, Boto GR (2010) Do antibiotic-impregnated 319 catheters prevent infection in CSF diversion procedures? Review 320 of the literature. J Infect 61:9-20.

The correct title of the article is:

Do antibiotic-impregnated catheters prevent infection in CSF diversion procedures? Review of the literature.

The online version of the original article can be found at http://dx.doi. org:10.1007/s00701-010-0905-1.

\footnotetext{
M. Rivero-Garvía $(\varangle) \cdot J$. Márquez-Rivas $\cdot$ A. B. Rueda-Torres Department of Neurosurgery, Hospital Virgen del Rocio,

$\mathrm{C} /$ Manuel Siurot $\mathrm{s} / \mathrm{n}$,

41013, Seville, Spain

e-mail: monicargarvia@msn.com

M. E. Jiménez-Mejías

Department of Infectious Diseases, Hospital Virgen del Rocio,

C/Manuel Siurot $\mathrm{s} / \mathrm{n}$,

41013, Seville, Spain

O. Neth

Department of Pediatric Infectious Diseases, Hospital Virgen del

Rocio,

C/Manuel Siurot $\mathrm{s} / \mathrm{n}$,

41013, Seville, Spain
} 